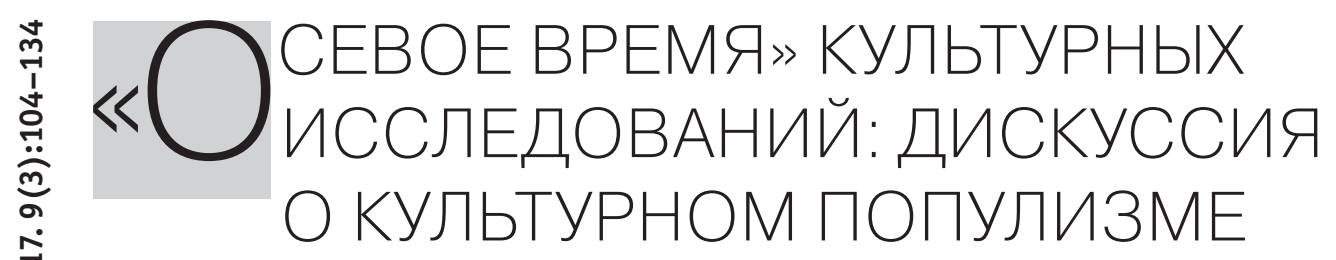

\title{
Борис Степанов
}

Борис Степанов - ведущий научный сотрудник Института гуманитарных историко-теоретических исследований НИУ ВШЭ, доцент Школы культурологии НИУ ВШЭ. Адрес для переписки: НИУ ВШЭ, Старая Басманная, 21/4, корпус Л, каб. 505, Москва, 105066, Россия. bstepanov@hse.ru.

Исследование выполнено в рамках Программы фундаментальных исследований Национального исследовательского университета «Высшая школа экономики» (НИу ВШЭ) с использованием средств субсидии, выделенной ниу ВШЭ на государственную поддержку ведущих университетов Российской Федерации в целях повышения их конкурентоспособности среди ведущих мировых научно-образовательных центров.

Обзор посвящен реконструкции дискуссии о культурном популизме в англоязычных исследованиях культуры во второй половине 1980-х - начале 1990-х годов. Будучи связанной с осмыслением поворота к изучению популярной культуры, эта дискуссия в значительной степени обозначила рамки самоопределения для исследователей в ситуации академической и публичной экспансии cultural studies. Предпринятый анализ преследует двоякую цель: (1) проанализировать историческую конъюнктуру этой дискуссии и различные аспекты осмысления cultural studies как критического и исследовательского проекта и (2) указать на значение этой дискуссии для осмысления современного состояния cultural studies и их ответвлений - таких как исследования фанатских сообществ, новых медиа и т п.

Ключевые слова: культурные исследования; популизм; популярная культура; субъективность; рецептивные исследования; субкультуры; исследования фанатских сообществ

Cultural studies представляют собой интересный с точки зрения истории знания феномен: сформировавшись в качестве локального британского интеллектуального движения и занимая достаточно маргинальное положение в академическом поле, в середине 1980-х культурные исследования пережили бурный процесс интернационализации и оказались в центре трансформаций современного университета, причем экспансия этого направления была воспринята неоднозначно как участниками самого движения, так и внешними наблюдателями. Превращение критически заостренного по отношению к академической науке проекта в одну из академических дисциплин сопровождалось быстрой сменой интеллектуальной, политической и медийной конъюнктуры и породило оживленные дискуссии о принципах и статусе этой области знания. Вопрос о дисциплинаризации культурных исследований, который оказался в центре обсуждения судьбы этого проекта и 
его будущего, не мог не повлиять на перспективу осмысления его истории. Проблематика поворотных периодов в истории знания представляется удобным контекстом для анализа этого влияния. В противовес генеалогическим версиям истории этого течения, которые делают акцент на работах его отцов-основателей, создании и развитии Бирмингемского центра современных культурных исследований, с одной стороны, и формирующимся поверх дисциплинарных границ историям «культурного поворота» - с другой, мы постараемся реконструировать поворотный пункт, значимый для формирования культурных исследований как дисциплины. В центре нашего обсуждения будет развернувшаяся во второй половине 1980-х - начале 1990-х годов дискуссия о культурном популизме. Именно в рамках этой дискуссии была проговорена та система координат, которая станет значимой для описания рамок и альтернатив самоопределения исследователей культуры в последующие десятилетия.

В качестве преамбулы нужно сказать несколько слов о той интеллектуальной ситуации, в которой разворачивалась дискуссия о культурном популизме. Как известно, культурные исследования изначально возникли как проект, связанный с критикой современной организации гуманитарного знания. Постановка вопроса о культуре означала не просто развитие какой-то специализированной области знания, но претензию на переосмысление антропологического горизонта саморефлексии современного общества, обозначаемого понятием «культура». Будучи тесно связаны с развитием «критической теории», культурные исследования аккумулировали опыт различных интеллектуальных движений, возникших в связи с проблематизацией ценностного содержания и социальных функций культуры феминистской и постколониальной критики, контркультурных и субкультурных движений и т. д. В этом смысле cultural studies стали одним из локомотивов так называемого «культурного поворота», оказавшего влияние на различные области гуманитарного знания (Bonnell and Hunt 1999; Бахманн-Медик [2015] 2017). Как пишет Колин Спаркс, «в течение этих двух десятилетий культурные исследования превратились из своего рода маргиналий на полях британского литературоведения в ведущее направление гуманитарного знания не только в Британии, но также и в США и Австралии» (Sparks 1996:71). Как показывает в своей влиятельной работе Билл Ридингс ([1997] 2010), развитие культурных исследований стало симптомом трансформации всей системы университетского образования и причиной разного рода интеллектуальных конфликтов и противостояний - как между культурными исследованиями и традиционными дисциплинами (социологией, литературоведением, в меньшей степени историей и т. д.), так и внутри самих cultural studies. Утверждение их академического статуса сопровождалось попытками зафиксировать нормативное содержание становящейся дисциплины, стремлением исследователей обозначить ее место, задачи, теоретические основания, принципы эмпирического анализа.

Предметом нашего рассмотрения будут дискуссии, развернувшиеся среди представителей культурных исследований на рубеже 1980-1990-х годов, которые мы и будем рассматривать как своего рода поворотный пункт в развитии этого направления (McRobbie 1996:238-239). Именно тогда культурные исследования пе- 
реживают процесс интенсивной институционализации и интернационализации. Знаковым в этом отношении событием стала конференция по культурным исследованиям в Урбана Шампейн (Иллинойс, США), в которой участвовали более 900 исследователей. Уильям Уорнер и Клиффорд Зискин (Warner and Siskin 2008:100) сравнивали эту конференцию с Тридентским собором, а выпущенный по итогам мероприятия сборник публикаций объемом более 800 страниц стал, по мнению Нормана Дензина, «своего рода библией культурных исследований» (Chamberlain 2004). Результаты бурной дисциплинарной экспансии новой дисциплины в Америке поражали воображение не только представителей консервативных кругов, видевших в этом симптомы моральной и интеллектуальной деградации и всеобщей релятивизации, но и родоначальников проекта. Бурный рост числа кафедр и профессорских позиций, создание образовательных программ в области культурных исследований не мог не вызывать удивления у британских ученых, которым приходилось в 1970-1980-х годах в условиях образовательной политики правительства Маргарет Тэтчер бороться за академическое признание (Chen and Hall 1996:397) ${ }^{1}$. Сравнивая конференцию в Урбана Шампейн с борхесовской картой Империи, занимавшей все ее пространство, Джон Страттон и Иен Энг писали о «новой американской гегемонии в пространстве англоязычных культурных исследований» (Stratton and Ang 1996:362-364). Не менее шокирующими оказывались содержательные трансформации знания о культуре. Несмотря на то, что исследовательская традиция, связанная с Бирмингемским центром культурных исследований, утверждалась на конференции в качестве отправной точки становления дисциплины (показательно, что в качестве приглашенного лектора на ней выступал один из основателей Центра - Стюарт Холл), образ знания о культуре вызывал у британских исследователей некоторую оторопь (Inglis 2007:108; об американизации см.: 0'Connor [1989] 1996). Характеризуя свои впечатления от сборника материалов конференции в Урбана Шампейн, Анджела МакРобби писала:

В момент первого знакомства со сборником «Культурные исследования», книгой, которая уже признана «блокбастером», я была охвачена паникой. Где я находилась последние пять лет? Подавляющее большинство того, что представлено здесь как культурные исследования, совершенно не совпадает с тем, что я преподаю, с тем, что я считаю полезным для понимания повседневного мира и повседневной культуры вокруг меня (McRobbie 1994:47)2.

Вместе с тем формирование культурных исследований в других странах и на иных континентах порождало и другие напряжения. Как отмечали Страттон и Энг, «в то время как британцы выражают недовольство новой американской гегемони-

${ }^{1}$ Вместе с тем Стюарт Холл отмечает, что встраивание cultural studies в британскую систему образования, ускорившееся на рубеже 1980-1990-х годов, происходило в известной мере под влиянием американизации университетской системы (Chen and Hall 1996:405-406).

${ }^{2}$ С упоминания об аналогичной реакции одного из основателей Бирмингемского центра на многостраничный сборник текстов докладов конференции 2000 года начинает свою книгу о современном состоянии культурных исследований Грэм Тернер (Turner 2012:1). 
ей, австралийцы (и в меньшей степени - канадцы), жалуются не меньше - если не больше - на британское доминирование» (Stratton and Ang 1996:379). Эта ситуация породила раскол в растущей среде исследователей культуры, выразившийся в интенсивных дискуссиях о том, что представляют собой культурные исследования и какими они должны быть, каковы их место и функции в академическом и публичном пространстве, каким образом должна выстраиваться интеллектуальная преемственность и какое значение имеют локальные контексты для формирования знания о культуре.

В центре этих дискуссий оказалась практика изучения популярной культуры. Речь шла не только о собственно методологических вопросах, но также о междисциплинарной перспективе развития знания о культуре и критических и политических функциях исследований культуры. В конце 1980-х - начале 1990-х годов в публикациях британских интеллектуалов этот клубок вопросов был обозначен термином «культурный популизм». Наиболее систематическим опытом рефлексии по этому поводу стала вышедшая в 1992 году книга Джима МакГигана «Cultural Populism» (McGuigan 1992), посвященная осмыслению эволюции cultural studies в 1960-1980-е годы ${ }^{3}$. Проявленная этой дискуссией система координат носит, на наш взгляд, парадигмальный характер: она значима не только для понимания тех развилок, на которых оказались культурные исследования конца 1980 - 1990-х годов, но стала инструментом осмысления взаимоотношений cultural studies c такими сложившимися десятилетиями позже направлениями, как исследования культурных индустрий, фанатских сообществ (fan studies) и культур соучастия (participatory cultures).

Реконструируя дискуссию о культурном популизме в целом и в отдельных ее изводах, мы ставим перед собой двоякую задачу. С одной стороны, эта дискуссия указывает на возможности политического, интеллектуального и методологического самоопределения, которые были сформированы внутренней логикой эволюции культурных исследований как области знания. С другой стороны, представляется важным обратить внимание на связь этой эволюции с исторической конъюнктурой, которая определялась общими политическими и культурными трансформациями, эволюцией в системе медиа и повседневной жизни людей, а также выступала объектом анализа для исследователей культуры. Более конкретно: речь идет об осмыслении проблематики постмодернизма, которая в тот момент была на острие общественной дискуссии и указывала на настойчивую потребность в осмыслении нового состояния общества и культуры. В середине второй половине 1980-х годов появляются программные тексты Фредрика Джеймисона, Жана Бодрийяра, Дэвида Харви, Алена Турена, Андре Горца, которые (наряду с работами Мишеля Фуко, Франсуа Лиотара, Жиля Делеза и Феликса Гваттари и других) задают контекст дискуссии о постмодерне. В более локальном контексте полемики британских интеллектуалов это новое состояние общества

${ }^{3}$ На эту работу мы в значительной степени будем опираться в данной статье. Впоследствии МакГиган неоднократно обращался к этой теме, развивая концепцию «крутого» (cool) капитализма (McGuigan 1997, 2011). Проблематика культурного популизма оказалась одной из центральных тем сборника статей «Cultural Studies in Question» (Ferguson and Golding 1997). 
обозначалось термином «Новые времена» (New Times) ${ }^{4}$. МакРобби давала этому обозначению следующую характеристику:

Будучи скорее британским, нежели интернациональным в своих коннотациях, этот термин отсылает к различным политическим сдвигам, произошедшим в Британии в течение последних 10 лет, включая успех «тэтчеризма», упадок традиционного рабочего движения, появление политики идентичности и потребления и, что наиболее важно, вызову всего этого для левых (McRobbie 1994:24).

Таким образом, наша задача будет заключаться в том, чтобы посмотреть, каким образом британские исследователи культуры формировали новую систему ориентиров, пересматривая принципы марксистского анализа культуры и вырабатывая адекватные новым условиям интеллектуальные и политические стратегии.

\section{РЕФЛЕКСИЯ О КУЛЬТУРЕ И СУБЪЕКТИВНОСТИ В СОЦИОКУЛЬТУРНОМ КОНТЕКСТЕ 1980-1990-Х ГОДОВ}

В своей программной статье «Что такое культурные исследования?» Ричард Джонсон раскрывает теоретическую логику, которая приводит исследователей культуры к модели «циркуляции» или «круговорота культуры» ([1983] 2012). Горизонт этой концепции задается идеей субъективности, реализующей себя в многообразии культурных форм, истоки которой Джонсон находит в ранних работах Карла Маркса. В рамках этой идеи осуществляется критика существующих подходов к исследованию культуры, которые согласно схеме циркуляции культуры тяготеют к одному из четырех полюсов: «производство», «тексты», «прочтения» и «живые культуры». Включая в себя разные перспективы анализа, модель циркуляции культуры представляет собой своего рода матрицу взаимосоотнесения подходов к интерпретации культурных феноменов, относящихся к различным областям знания (Джонсон [1983] 2012:80-135)5. Вместе с тем принцип субъективности разворачивается здесь в форме последовательной критики редукционистских моделей интерпретации культуры. Отправной точкой при этом становится критика концепций, базировавшихся на метафоре производства культуры и связанных с марксистской традицией (Теодор Адорно, Макс Хоркхаймер, Луи Альтюссер и др.) ${ }^{6}$. Предметом критики выступает представление о жесткой детерминированности культуры экономикой и политикой и презумпции пассивности субъекта в системе производства культуры. Затем критическому анализу подвергаются подходы, делающие акцент на исследовании текстов. Здесь сама специфика культурных форм

${ }^{4}$ В 1989 году под редакцией Стюарта Холла и Мартина Жака был выпущен сборник «Новые времена: меняющееся лицо политики в 1990-е годы» (Hall and Jacques 1989), ставший предметом оживленной интеллектуальной полемики.

${ }^{5}$ Этот аспект схемы круговорота культуры будет представлен шире в более поздней работе Ричарда Джонсона и его коллег (Johnson et al. 2004).

${ }^{6}$ Критический анализ этой стигматизации Адорно см.: Hills (2002:6-11). 
и их смысловое содержание попадают в центр внимания, однако это оказывается возможным благодаря выключению этих форм и их социального функционирования или, в крайнем случае, признанию их первичности по отношению к реальным субъектам культуры, опять-таки не оставляющего места для их собственной активности. Отсюда намечается переход к изучению прочтений и «живых культур», то есть различных контекстов и практик, в рамках которых тексты осваиваются различными субъектами․ Таким образом, идея субъективности в анализе Джонсона оказывается локомотивом логики культурализма (или, иначе, - автономизации культуры), призванной выявить то исследовательское пространство, где культура как обозначение совокупности жизненных смыслов будет иметь значение самостоятельного объяснительного принципа.

Намечая перспективу рефлексии об автономизации культуры, Джонсон предвосхищает то, что станет предметом дискуссии в рамках споров о культурном популизме и «новом ревизионизме», которые развернутся на рубеже 1980-1990-х годов. Эти дискуссии были тесно связаны с формированием поля исследований популярной культуры. Тема популярной культуры традиционно занимала ключевое место в работах представителей культурных исследований - достаточно вспомнить работы основателя Бирмингемского центра Ричарда Хоггарта или работы Стюарта Холла 1960-х годов. Уже здесь намечаются важнейшие для проблематики популярной культуры темы неоднородности массовой культуры, наличия в ней аутентичных и неаутентичных компонентов и способности субъекта к их различению (McGuigan 1992:49-53). Однако по-настоящему интенсивное освоение этой темы пришлось на 1980-е годы. Политическим импульсом для этого была потребность в осмыслении культурно-политического режима, сложившегося в период правления Маргарет Тэтчер. Сочетание капиталистических ценностей с консервативными идеологическими установками в работах одного из лидеров cultural studies Холла получило обозначение «авторитарного популизма». Емкая характеристика, которую дает этой ситуации МакГиган вслед за Холлом, звучит достаточно актуально и в современном российском контексте:

Утверждение необходимости осмыслить, как тэтчеризм обращался к массовым ожиданиям, демонстрировало понимание того, где «обычные люди» на самом деле находились в своей повседневной жизни, того, чем невозможно было пренебречь в свете «великой старой идеи» социализма. Смысл термина «новые времена» в соответствии с его [Стюарта Холла] рассуждениями 1985 года также был в том, чтобы ухватить современные формы субъективности и реальные условия существования людей (McGuigan 1992:38).

Приведенная цитата из текста МакГигана описывает политический контекст интеллектуального поворота, связанного с интересом к популярной культуре.

7 Эти подходы Джонсон также не оставляет без критического рассмотрения. Интересно, что, по мнению Грэма Тернера, несмотря на свой интерес к исследованию народной культуры и исторических конструкций субъективности, Джонсон, в отличие от Холла, был очень скептически настроен по отношению к существовавшим в Бирмингемском центре традициям этнографического анализа (Turner 2003:64-65). 
Осознание недостаточности традиционной экономической критики капитализма инспирировало разработку почерпнутой у Антонио Грамши концепции гегемонии, обозначавшей задачу осмысления идеологических установок простых людей, обеспечивающих устойчивость и идеологическую привлекательность капиталистического порядка ${ }^{8}$. Соответственно, интерес к популярной культуре был связан с поиском низовых культурных импульсов, представляющих собой альтернативу существующей идеологии.

Последовательное признание популярной культуры в качестве интерпретативной рамки окончательно легитимировало возможность рассматривать любой феномен современной культуры как выражение субъективности (Hall 1996). Следствием этого было признание в той или иной степени эмансипаторного потенциала капитализма и массовой культуры. Капитализм выступал не как монолитная система, которая ограничивает самореализацию субъективности массово воспроизводимыми формами, но и как пространство, где создаются условия для культурной активности масс. Важной сферой этой активности становится культурное потребление. В этом словосочетании для исследователей культуры были важны обе составляющие. Потребление рассматривалось уже не только как сфера отчуждения субъекта, но и как форма воспроизводства последнего, предполагающая выбор и формирование собственной идентичности (McRobbie 1994:24; Nava 1987:207-210). Большое значение, с точки зрения утверждения позитивного смысла потребления, имела легитимация удовольствия (Turner 2003:184-187). В интерпретации удовольствия теоретики cultural studies (в частности Терри Ловелл) стремились выйти за пределы предшествующих трактовок - и марксистских (удовольствие как выражение неподлинных потребностей), и психоаналитических (сведение удовольствия к проявлениям сексуальности) (McGuigan 1992:68-69). Вместе с тем в работах МакРобби мы находим призыв к постановке вопроса о новом характере труда в рамках «символической экономики», к проблематизации соотношения потребления и удовольствия, потребления и покупки, роли смыслополагания и места потребления в повседневной жизни различных групп и т. д. (McRobbie 1994:29-33).

Будучи связанным с выбором, интерпретацией и воспроизводством субъектом самого себя, потребление оказывается важной сферой символической активности. Наиболее радикальное выражение эта идея получила в концепции Джона Фиске, ставшей едва ли не основной мишенью для критиков культурного популизма. Опираясь на идею Пьера Бурдье об относительной автономии культурного поля, Фиске формулирует концепцию «культурной экономии». В отличие от финансовой, культурная экономия имеет дело не столько с меновой, сколько с потребительной ценностью вещей и текстов и, таким образом, сфокусирована на значениях, удовольствии и социальной идентичности (Fiske 1987:311)9. Тем самым в

${ }^{8}$ Другой важной концепцией, которая разрабатывалась Стюартом Холлом в 1970-е - начале 1980-х годов, стала почерпнутая у Эрнесто Лакло концепция артикуляции, обозначавшая зазор между экономической и идеологической сферами и указывавшая на необходимость анализа идеологических трансформаций, который не редуцировал бы их до экономических условий.

${ }^{9}$ Ср. концепцию символической экономии Жана Бодрийяра. 
центре внимания исследователей культуры оказывается присвоение культурной продукции различными аудиториями, которое позволяет рассматривать их как производителей ее значения, а потребление, соответственно, как значимый фактор в системе экономических взаимоотношений (Storey 2001:175) ${ }^{10}$. Важным источником для этой концепции становятся идеи Мишеля де Серто о «текстуальном браконьерстве», впоследствии развитые Генри Дженкинсом. Не менее важен политический смысл, который Фиске придает потреблению культуры. 0н провозглашает популярную культуру сферой «семиотической демократии» (semiotic democracy) и «семиотической партизанской войны» (semiotic guerrilla warfare), представляющей собой сопротивление процессам гомогенизации, связанным с работой культурных индустрий. Тем самым популярная культура являет, по его мнению, альтернативу традиционным формам политической активности. Предлагаемый им подход рассматривает популярную культуру как «потенциально, а часто и актуально, прогрессивную (хотя и не в радикальной форме)» (176). Этот подход «явлется принципиально оптимистическим, поскольку в энергии и жизненной активности простых людей он находит возможность социальных перемен и мотивацию к их осуществлению» (Fiske 1989:8).

Описанный нами выше идейный комплекс МакГиган обозначает термином «культурный популизм», определяя его как характерную для некоторых исследователей культуры убежденность в том, что «символический опыт и практики обычных людей являются более значимыми в исследовательском и политическом плане, нежели культура с большой буквы» (McGuigan 1992:4). По его мнению, признание необходимости выйти за рамки собственных интеллектуальных стереотипов и обратиться к пониманию потребностей, запросов и условий жизни простых людей приводит к тому, что популярная культура как объект изучения выходит из зоны рефлексивного исследовательского контроля и приобретает статус точки отсчета в культурном и политическом смысле. Сентиментальное отождествление с ней и отказ от помещения культурных феноменов в политико-экономическую макроперспективу подрывает критический посыл самого проекта культурных исследований. В этом МакГиган видит влияние постмодернизма, который, руководствуясь «модной» логикой снятия бинарных оппозиций в духе Жака Деррида, устраняет необходимую для критики дистанцию. Последнее он считает весьма симптоматичным свидетельством состояния современного академического мира (173).

Очень важно понимать, что диагностическая жесткость приведенных формулировок имеет провокативный характер и в определенном смысле противоречит целям, которые преследует в своей книге МакГиган. В предисловии к ней он, с одной стороны, предупреждает, что сама практика политического бытования термина «популизм» свидетельствует о легкости его демагогического использования, которого он хотел бы избежать. С другой стороны, МакГиган готов и себя в определенном смысле признать культурным популистом, считая саму по себе задачу ис-

${ }^{10} 0$ значении множественности аудиторий с точки зрения признания отсутствия фиксированных значений у текстов см.: McRobbie (1994:21). 
следования популярной культуры безусловно ценной. В этом смысле целью своей книги он объявляет интеллектуальную рефлексию, которая могла бы способствовать формированию «критического популизма» (McGuigan 1992:5). Достижению этой цели как раз и должен способствовать подробный разбор эволюции исследований популярной культуры, который он предпринимает на страницах книги. Таким образом, нужно учитывать условность данного выше описания культурного популизма как некоторого единого идейного комплекса, поскольку в этом описании оказались объединены такие разные исследователи, как Холл и Фиске ${ }^{11}$. В своем рассмотрении МакГиган обращается и к теоретической рефлексии по поводу понятия «популярная культура». В работах представителей cultural studies (прежде всего, Тони Беннета) была раскрыта принципиальная проблематичность определения популярной культуры через оппозиции культуре «современной», «официальной», «элитарной», «массовой» и т. п. (Parker 2011). Однако нас в большей степени будет интересовать логика эмпирических исследований популярной культуры, которая позволяет сделать дискуссию о культурном популизме отправной точкой для выявления антропологического содержания исследований популярной культуры. Далее мы рассмотрим, как проблематика культурного потребления отрабатывалась в двух областях, которые имели ключевое значение для культурных исследований - в исследованиях молодежной культуры и исследованиях телевидения.

\section{ПРОБЛЕМАТИКА ПОПУЛЯРНОЙ КУЛЬТУРЫ В ИССЛЕДОВАНИЯХ СУБКУЛЬТУР И РЕЦЕПЦИИ МЕДИАТЕКСТОВ}

Эволюция исследований молодежных субкультур в рамках cultural studies является ярким примером работы по освоению многообразия современной культуры, в рамках которой актуализировалась проблематика субъективности и символической активности. Ее апогеем стал грамшианский поворот и последовавшая за ним дискуссия о культурном популизме. Политическим импульсом для этой работы стали попытки переосмысления идеологических презумпций британских «новых левых», связанные в частности с поиском альтернатив рабочему классу как субъекту социальных изменений ${ }^{12}$. В осмыслении субкультур как самостоятельных агентов социального изменения и осознанию их специфичности по отношению к классам, связанным с их поколенческим характером, важную роль играло осозна-

${ }^{11}$ Впрочем, эта конструкция сама по себе симптоматична с точки зрения набирающего обороты в момент написания книги процесса интернационализации культурных исследований, поскольку Джон Фиске стал одним из популяризаторов британских культурных исследований в США.

120 программе «Новых левых» см. статью Виталия Куренного (2012:58-59). Он также прослеживает эволюции концепции субкультур в работах представителей cultural studies, однако делает упор в большей степени на изменившуюся оценку политического потенциала субкультур, в то время как в нашем анализе в центре внимания находится, как было отмечено выше, осмысление субъективности и трансформация понимания политического. 
ние значимости символического измерения их существования. Не менее значимой была критика господствовавшего в тот момент представления о них как о форме социальной патологии: разоблачая предпосылки транслируемой исследователями вкупе с масс-медиа «моральной паники» по поводу субкультур, представители культурных исследований призывали к изучению их как символического вызова по отношению к доминирующей культуре.

Анализируя два наиболее значимых исследования молодежных культур 1970х годов Пола Уиллиса и Дика Хебдиджа, Макгиган указывает два направления анализа. В то время как у Пола Уиллиса акцент делается на выявлении форм культурного сопротивления в повседневной культуре рабочей молодежи, у Хебдиджа акцент в большей степени сделан на многообразии субкультурной креативности. В рамках этой концепции большое значение имела проблематика потребления, рассматривавшаяся как форма знаковой активности, причем в отличие от более ранних работ представителей школы (например, сборника «Resisting through Rituals») у Хебдиджа значительно основательнее была задействована структуралистская концепция. Понятие «бриколажа» использовалось представителями бирмингемской школы для характеристики тех символических комбинаций, которые послужили инструментом формирования субкультурных стилей. Однако в полной мере проблематика символической активности была легитимирована в 1980-е годы. Важную роль здесь сыграли инспирированные феминизмом исследования Анджелы МакРобби, Мики Навы и других исследователей, которые не только сделали женские сообщества значимым для исследователей молодежных культур объектом, но и способствовали пересмотру ряда важных диспозиций, лежавших в основе исследования. В частности объектом критики феминистских исследователей стала романтизация грубой маскулинности, которая в исследованиях мужских субкультур рассматривалась как форма протеста. В то же время обращение к этнографическому изучению женских форм досуга способствовало пересмотру представления о женщинах как пассивных субъектах потребления.

Обращение к исследованию женских культур не только сделало объектом более рутинные и мейнстримные феномены, но и в конечном счете повысило значимость сферы воображения ${ }^{13}$. Поворот к изучению воображения произвел двоякий эффект. С одной стороны, легитимация воображения была связана с более позитивной оценкой мейнстримной культурной продукции ${ }^{14}$. Ярким примером здесь является проведенное МакРобби исследование журнала для девочек-подростков Jackie. В нем исследовательница признавала, что «реальная» критика этой продукции (представленность реальных проблем и «жизненных» ситуаций») не позволяет понять те средства, которые используются журналом для удовлетворения потребностей своих читательниц. С другой стороны, именно здесь оказалась

${ }^{13}$ На дефицит внимания к проблематике воображения МакРобби указывает в своей критике концепций Уиллиса и Хебдиджа (McRobbie [1980] 1991:18).

${ }^{14}$ Как показывает МакГиган, этому концептуальному сдвигу способствовали и институциональные трансформации, сделавшие медиа более открытыми для социально-критических проектов, участниками которых оказались и сами представители Бирмингемского центра, в частности Хебдидж и МакРобби (McGuigan 1992:92-91, 110-111). 
принципиально важной презумпция отказа от текстуального детерминизма и признание активности женщин как потребителей, их способность присваивать культурную продукцию и использовать ее по собственному усмотрению.

Таким образом, поле исследований популярной культуры было фактически связано с отказом от ориентации на радикальную трансформацию капиталистического порядка и с попыткой инвентаризации импульсов к его трансформации, сформированных развитием этого порядка и существующих внутри него. Уже в 1980 году МакРобби пишет о необходимости дополнить политическую триаду класса, пола и возраста другой триадой - популизм, досуг и удовольствие (McRobbie [1980] 1991:31-32). С одной стороны, речь шла о проблематизации гомологии между консюмеризмом и конформизмом, пассивностью, которая сопровождалась реабилитацией культурных текстов и практик, традиционно связанных с консюмеризмом (таких, например, как реклама), и призывами обратиться к исследованию взаимодействия молодежи и других социальных групп с формами доминирующей культуры, в которых тоже оказалось возможным увидеть игру означающих (McGuigan 1992:111-113) ${ }^{15}$. С другой стороны, исследования «живых культур» стимулировали критику существующей политики популяризации искусства и создания искусства (для) масс. Пол Уиллис, опираясь на идеи Ирвинга Гоффмана о драматургии повседневной жизни и Бертольта Брехта о спектакле повседневности, выдвигает идею «приземленной эстетики» (grounded aesthetics) в противовес производимой интеллектуалами канонизации продуктов народной культуры, превращающей их в аналоги произведений высокого искусства (McGuigan 1992:115-116; Storey 2001:178-179). Отрицая имманентно присущую объектам эстетическую ценность, Уиллис делает акцент на их потреблении/использовании, в котором раскрывается символическая активность людей как агентов повседневного взаимодействия. Здесь его концепция противопоставлена тезису Бодрийяра о поверхностности культурных значений: именно повседневная жизнь, по мнению Уиллиса, оказывается насыщена подлинной активностью по порождению смыслов.

Показательно, что и в политическом, и в методологическом плане Уиллис дистанцируется прежде всего от левых интеллектуалов. В политическом плане он критикует их «популизм», поскольку в реальности они не способны осмыслить действительно существующую культуру простых людей. В методологическом плане обращение к работам Гоффмана сопровождается у Уиллиса отходом от «ортодоксальной» грамшианской перспективы с ее презумпцией доминирующей идеологии и сдвигом в сторону микросоциологической программы исследования популярной культуры, ориентирующейся на анализ конкретных практик (McGuigan 1992:118-119).

Другой важнейшей с точки зрения изучения популярной культуры и формирования проблематики культурного популизма областью стали исследования телевидения. Как отмечает МакГиган, именно телевидение стало в 1970-1980-е

${ }^{15}$ Одновременно, как отмечает МакГиган, происходила и реабилитация маркетинговых исследований. 
годы приоритетным объектом анализа для представителей cultural studies, в отличие от их оппонентов, группировавшихся вокруг журнала Screen и в большей степени ориентированных на изучение кинематографа. Наряду с пионерской работой Реймонда Уильямса, продемонстрировавшего значение телевидения для трансформации повседневного уклада, программное значение для бирмингемской традиции имели работы Стюарта Холла, в которых была сформулирована модель кодирования-декодирования телевизионных сообщений. Эта модель вписывалась в сформировавшуюся в британской социологии критическую парадигму медиа-исследований, которая, как показывал Джеймс Карран), противостояла господствовавшей в этот период концепции баланса интересов. Последняя представляла медиа как организационно сбалансированную систему выражения плюралистичных ценностей, автономную по отношению к власти и ориентированную на равноправные отношения с аудиторией. Между тем британская критическая программа была ориентирована на рассмотрение медиа, и, в частности, телевидения как инструмента социального конфликта, обслуживающего интересы господствующего класса и являющегося инструментом трансляции доминирующей идеологии. Специфика концепции Холла, сформулированной в рамках грамшианской проблематики культурной гегемонии, заключалась в интересе к проблематике идеологического консенсуса и возможностей альтернативного по отношению к транслируемой идеологии прочтения медиасообщений (Curran 1990:136-139). Опираясь на идеи Валентина Волошинова, Умберто Эко и Ролана Барта, связанные с многозначностью культурных текстов и множественностью вариантов прочтений, Холл попытался наметить три возможных типа прочтений телевизионного сообщения, обусловленных классовой принадлежностью различных сегментов зрительской аудитории. Будучи ориентированной на изучение восприятия медиатекстов и его социологическую интерпретацию, концепция Холла опиралась на критику идей исследователей кинематографа, группировавшихся вокруг журнала Screen, которые руководствовались представлениями о текстуальной эффективности, обусловленности субъективности зрителя, понимаемой в духе лаканианского психоанализа, спецификой медиа в целом и отдельных типов сообщений.

В конце 1970-х - начале 1980-х годов появляются эмпирические исследования аудиторий, призванные осуществить проверку модели кодирования/декодирования. Одним из наиболее заметных среди них стало исследование Дэвида Морли, посвященное восприятию новостной программы «Nationwide» различными социальными группами - менеджерами, студентами, рабочими и т. д. (об истории проекта см.: Brunsdon and Morley 2005:1-18). Его результаты оказались достаточно неоднозначными: продемонстрировав правомерность гипотезы о различных прочтениях этой программы, исследование Морли и последовавшая за ним дискуссия выявили вместе с тем принципиальную ограниченность исходной модели. Для адекватного понимания того, как воспринимаются телепрограммы, оказалось, во-первых, необходимым учесть не только многообразие социальной идентичности аудиторий, но и их культурную компетентность. Во-вторых, необходимо было также выйти за пределы узкоидеологической трактовки медиасообщений и перейти к анализу социального контекста телесмотрения, а значит, перене- 
сти акцент с обсуждений в фокус-группах на изучение того, как происходит просмотр телевидения в естественной обстановке, какими социальными контекстами структурируется опыт аудиторий и т. д. Соответственно, менялись и политико-антропологические принципы исследований. Представление о связи прочтений с классовой принадлежностью, лежавшее в основе использованной Холлом концепции Фрэнка Паркина, усложнялось за счет введения заимствованной у Бурдье идеи культурной компетенции зрителя. Это стало еще одним шагом на пути автономизации субъекта восприятия. Политическая перспектива такого рода автономизации задавалась теорией Эрнесто Лакло и Шанталь Муфф, утверждавших отсутствие однозначной связи между транслируемой посредством медиа идеологией и идентичностью субъекта.

Изменение оптики, намеченное в работе Морли, просматривается и в ряде других исследований, посвященных анализу обусловленности восприятия телевидения социальными характеристиками различных аудиторий. В частности, существенное значение имели работы, посвященные детской аудитории, влияние телевидения на которую традиционно было объектом моральной паники. Как показывал в своем исследовании Дэвид Люстед, телевидение подозревали в пробуждении у детей агрессивных инстинктов, подавлении самостоятельности суждения, а также в трансляции нежелательного контента, связанного с насилием и сексуальностью. В исследованиях второй половины 1980-х мы находим не только признание соответствия детских программ и сериалов интеллектуальным потребностям детей, но и утверждение их способностей к различению реальности и фантазии, а также к самостоятельному осмыслению взрослых программ и заполнению возникающих смысловых лакун (McGuigan 1992:152). Другим важным аспектом анализа было изучение трансформации инфраструктуры телевидения, изменившей характер его потребления. Речь идет в частности о технологиях, сделавших возможной присвоение и переработку телевизионной продукции (таких как домашнее видео). Наконец, еще одной важной тенденцией, на которую указывает Стори (Storey 2001:180-182), стало обращение к тем сферам, в которых потребительская активность носила наиболее очевидный характер, а именно к изучению деятельности фан-сообществ, значимым образцом которых стали появившиеся на рубеже 1990-х годов работы Дженкинса.

Другой важной тенденцией стал пересмотр иерархии телевизионной продукции и телевизионных аудиторий в контексте проблематики популярной культуры. Первостепенное значение здесь приобрели исследования мыльных опер. Этот жанр находился внизу иерархии телевизионных жанров в связи с невысокими - с точки зрения и медиаисследователей, и феминистских критиков - эстетическими и информационными (отсутствие реализма) качествами. Соответственно, обращение к нему позволяло не только обратить внимание исследователей на традиционно находившуюся за пределами внимания специфику женского опыта восприятия телевидения, но и поставить вопрос о природе зрительского удовольствия. «Антиреализм постоянно скатывается к неприятию всех или наиболее популярных форм и конвенций. Мы хотели исследовать мыльную оперу именно потому, что она популярна, делается для женщин и посвящена им, потому что она не явля- 
ется престижной, и мы хотели проанализировать, почему она является источником удовольствия для миллионов людей и соотнести это с производимыми ею идеологическими эффектами» (Dyer, Lovell, and McCrindle 1977:26; цит. по: McGuigan 1992:143). Одним из важных аргументов в обосновании эстетической ценности мыльной оперы стало утверждение о том, что именно в рамках этого жанра зритель контролирует его содержание. Апеллируя к активности зрительских аудиторий, обусловленной длительностью сериальной формы и возможностями изменения сюжета, Дороти Хобсон призывала пересмотреть традиционную квалификацию мыльной оперы как «закрытого» произведения: «В конечном счете, мыльная опера является, на мой взгляд, одной из самых прогрессивных форм телевизионной продукции, поскольку она всегда находится под контролем аудитории. Какое бы решение о его содержании не принял производитель, зритель всегда лучше знает, какое решение является наилучшим» (Hobson 1985:60; цит. по: McGuigan 1992:144).

Наряду с общими соображениями в защиту эстетической ценности сериалов, осмысление их роли в популярной культуре потребовало осмысления категорий оценки этого типа текстов разными аудиториями. Одной из ключевых категорий рефлексии была оценка реализма. Как показала в своем анализе сериала «Даллас» Иен Энг, поклонники признают его реалистичным, несмотря на расхождения между жизненным уровнем героев, спецификой обстоятельств их жизни и т. д. Причина этого заключается в эмоциональном реализме, обусловленным близостью для зрительниц показанных в сериале ситуаций. Важнейшим фактором диверсификации критериев реализма оказалась нараставшая интернационализация сериальной продукции, создававшая ситуацию конкуренции между локальными и универсальными (прежде всего, американскими) образцами. Универсалистская американская продукция выигрывала в обобщенности ситуаций, между тем локальные производители могли завоевать внимание зрителей точностью деталей, знанием местной специфики и конъюнктуры. Наконец, еще одним важным параметром диверсификации рецепции сериалов было восприятие различными аудиториями низкого культурного статуса сериалов: в то время как одни аудитории испытывали давление «идеологии массовой культуры» и рассматривали просмотр сериалов как «постыдное удовольствие», вырабатывая ироническую стратегию интерпретации, другие видели в этом самоценную форму культурной самореализации (McGuigan 1992:148).

Важным следствием обсуждения проблематики активности зрительских аудиторий стала тема общественного регулирования телевещания и роли рынка в обеспечении доступности и разнообразия телевизионной продукции. Актуальность этой темы для Британии середины 1980-х была обусловлена политикой правительства Тэтчер, направленной на сокращение общественного регулирования вещания и стимулирование рыночных механизмов поддержки телевещания. Как показывает МакГиган, в этом пункте поборники новой концепции популярной культуры расходились с представителями политэкономической критики культуры. В то время как последние (такие, например, как Никола Гарнхэм) были склонны отстаивать значение общественного телевидения, первые (например, Иен Ко- 
нелл) указывали на прогрессивное значение рыночных механизмов с точки зрения удовлетворения запросов телезрителей (Gray 1987:28-29). Менялась и «политическая программа» в отношении массового зрителя: задачи просвещения уступали место задачам обеспечения зрительской кооперации и коммуникации (Ang 1987:657-658).

\section{ДИСКУССИЯ О КУЛЬТУРНОМ ПОПУЛИЗМЕ: PRO ЕT CONTRA}

Намеченная выше характеристика интеллектуальной эволюции культурных исследований в 1980-е годы была призвана указать на то, каким образом логика субъективации и формирование более гибкой модели анализа культуры и общества были связаны в целом со становлением исследований популярной культуры и отдельными их направлениями - исследованиями молодежных культур и телевидения. Этот круг проблем и оказался в центре дискуссии о культурном популизме, призванной обозначить место сложившейся конфигурации подходов и исследовательских интересов в пространстве гуманитарного знания, оценить миссию этого исследовательского проекта в контексте исторических вызов постмодернизма/«новых времен». Дискуссия не была прерогативой лишь культурных исследований. В некоторых отношениях в ней можно усмотреть параллели с тем, что происходило в других областях гуманитарного знания. Так, например, обсуждение «прагматического поворота», развернувшееся в конце 1980-х годов в журнале Annales: Economies, sociétés, civilisations, также затрагивало целый ряд сходных проблем (соотношение микро- и макроподходов, статус социальных и культурных целостностей, вопрос о социальной детерминации и т. д.) (Бессмертный 2000; Савельева и Полетаев 2006:666-683). В этом контексте аналогичная дискуссия исследователей культуры интересна тем, что она в более очевидной форме вскрывала взаимосвязь между историческим и культурным самоопределением конкретного ученого и его аналитической программой, побуждала в более эксплицитной форме зафиксировать те диспозиции, которыми было обусловлено представление об исследовательской работе и критической миссии интеллектуала.

В дискуссии о культурном популизме сталкивались противоположные оценки исторической перспективы произошедшего поворота. Некоторые критики обвиняли «ревизионистов» в том, что они воспроизводят устаревшие подходы американских медиаисследователей середины XX века (Curran 1990). Однако более популярными были упреки в конъюнктурности. Они касались как интересов исследователей популярной культуры, «радостный популизм» которых характеризуется «новоприобретенным почтением к цифрам продаж», так и их связи с миром медиа, которая дискредитировала исследования культуры и снижала их критический потенциал (Frith and Savage 1992:107; цит по: McRobbie 1996:254)16. Вместе с тем важно понимать, что критика «внутри» cultural studies часто была не менее жесткой и не менее рефлексивной. Показательным примером здесь может слу-

${ }^{16}$ Комментируя эту критику Анджела МакРобби (1996:239) с иронией отмечала, что она исходит от людей подобных Саймону Фриту и Джону Сэвиджу, которые сочетают академическую профессию с рок-журналистикой. 
жить известная статья австралийской исследовательницы Меган Моррис «Banality in Cultural Studies». Автор говорит о банальности в двух значениях. С одной стороны, в повороте к исследованиям популярной культуры Моррис видит симптом банализации культурных исследований:

Время от времени, когда я читаю издания вроде «Нового социалиста» или «Марксизм сегодня» за последние два года, листаю журнал «Культурные исследования» или разглядываю пачки изданий по теории популярной культуры (pop-theory) в книжном магазине, меня посещает ощущение, что где-то в подвале у какого-то английского издателя есть жесткий диск, откуда тысячи версий одной и той же статьи об удовольствии, сопротивлении и политике потребления распространяются под разными именами с минимальными вариациями. Американцы и австралийцы также перерабатывают эту главную статью по теории популярной культуры, возможно с большими изменениями, поскольку английская теория популярной культуры по-прежнему отталкивается от левого популизма в своей попытке спасти смысл жизни от катастрофы тэтчеризма. Будучи оторвана от этого контекста, как и все остальные товары, и переработана в рамках иных политических культур, рудиментарная критическая сила этого популизма имеет тенденцию исчезать или мутировать (Morris [1988] 1996:156) ${ }^{17}$.

С другой стороны, понятие «банального» используется здесь для остранения проблематики популярного и выявления стратегий его конструирования. Обращаясь в числе прочих к работам Мишеля де Серто, сыгравшим важную роль в легитимации популярной культуры как объекта исследования, Моррис указывает на необходимость учитывать негативные значения популярного, которые оказываются на периферии внимания представителей cultural studies (Morris [1988] 1996:165).

В своей характеристике дискуссии о культурном популизме мы будем следовать классификации, предложенной МакГиганом, который разделил аргументы его критиков на три группы: политическая критика, суждения о качестве и социальное объяснение (McGuigan 1992:76). При этом, на наш взгляд, приводимые автором «Культурного популизма» примеры не всегда соответствуют заявленным им рубрикам. Это объясняется, по-видимому, тем, что с учетом перекличек, возникающих между аргументами разных типов, такого рода рубрикация будет обладать известной долей условности.

Политический аспект критики культурного популизма связан с указанием на следствия переоценки капитализма. Как было показано выше, поворот к исследованию популярной культуры был связан с осознанием неоднозначности капитализма и попыткой увидеть имманентные ему источники его трансформации, выражением чего и стала идея активности субъектов культуры, ведущих борьбу в рамках идеологической гегемонии. Из утверждения активности субъекта и актуализации темы удовольствия вытекала возможность признания того, что априорные оценки культурной продукции как «реакционной» или «прогрессивной»

${ }^{17}$ Осмыслению этой критики в контексте анализа роли книгоиздания в институционализации cultural studies посвящена статья Теда Стрифаса (Striphas 2002) 
должны быть пересмотрены с учетом характера рецепции последней. По мнению критиков, попытки поставить в центр внимания популярную культуру как сферу идеологического сопротивления, чреваты издержками. Семиотический анализ, направленный на обнаружение многозначности культурной продукции (в том числе таких откровенно консюмеристских ее форм, как реклама) обнаруживает в ней аспекты потребления, не сводимые к чисто коммерческой составляющей. Это, как отмечает МакГиган в своей критике работ Навы, ведет к неоправданной реабилитации такого рода феноменов (McGuigan 1992:120-121). В более общей перспективе здесь возникают вопросы о соотношении удовольствия и протеста, о том, до какой степени признание неоднозначности текстов и потенциала креативного потребления приводит нас к признанию того, что медиа дает потребителю желаемое им (Gray 1987:28). По мнению Джудит Виллиамсон, достойно сожаления то, что из словаря исследователей культуры уходят понятия «реакционный» и «прогрессивный», а критика подменяется поиском идеологических разночтений в тексте (Webster [1990] 1996:224). Попытки перенести акцент с изучения средств массовой информации на изучение активных аудиторий, выступающих средоточием сопротивления, чреваты романтической переоценкой последних. Это может сказываться, во-первых, на системе исследовательских приоритетов: в центре внимания оказываются «интересные» и/или прогрессивные явления, в то время как более консервативные и рутинные механизмы воспроизводства культуры выпадают из внимания. Во-вторых, это может касаться выводов относительно статуса этого опыта. Критикуя работы Джона Фиске, Меган Моррис (Morris 1996:164165) и Иен Энг (Ang 1990:247) указывают на склонность последнего приписывать конкретным моделям альтернативных прочтений медиасообщений более общий характер или отождествлять активность медиапотребителей с обладанием властью и контролем. Тем не менее ключевое значение здесь имел вопрос об оценке капиталистического порядка и его способности к трансформации. В то время как поборники идеи «Новых времен» делали акцент на диверсификации капиталистического порядка, экономисты из журнала Class \& Capital Анна Поллерт и Саймон Кларк рассматривали идеи о трансформации капитализма исключительно как идеологическое оправдание, призванное заставить простых людей полюбить общество, в котором отсутствуют социальные гарантии и царит безработица (McRobbie 1996:248-250).

Отвечая на эти упреки, сторонники исследований популярной культуры указывали на то, что в основе подобных упреков лежит политический элитизм с присущими ему представлениями о массовой культуре как форме манипуляции массами, а отстаиваемый здесь образ социальной критики неразрывно связан с левацким пессимизмом и моральным лефтизмом, а также с определенным типом категориального аппарата - экономическим или социологическим (Storey 2001:185) ${ }^{18}$. Вместе с тем Холл, МакРобби и другие представители cultural studies стремились отмежеваться от радикальных утверждений, в соответствии с которы-

18 В связи с этим сюжетом Дэвид Морли упоминает об упреках в «социологическом квиетизме» (Morley 1992:330). 
ми эти трансформации приобретали значение объективных закономерностей исторического процесса (рынок как источник культурного разнообразия или развития коммуникативных технологий, как фактор эмансипации пользователя, способствующий демократизации культуры и т. д.) (MacRobbie 1994:23-33, 43-59; Storey 2001:174).

Критика культурного популизма, относящаяся к суждениям о качестве, связана с оценкой роли интеллектуала в критике и воспроизводстве культуры, которая возникает вследствие размывания границ между массовой и высокой культурой, релятивизации иерархий культурных текстов. Это в свою очередь подводит к проблеме позиции и миссии интеллектуала, указывая на которую критики культурного популизма активно обращаются к концепции Бурдье. Утверждая устойчивость существующих культурных иерархий, Йостейн Грипсруд (Gripsrud 1989:202) и Саймон Фрит (Frith 1991:105, 109) настаивали на первенстве интеллектуала как носителя критического и/или аналитического суждения и на том, что во всех сферах культуры это суждение работает одинаково. С этой точки зрения утверждение ценности популярной культуры трактовалось как нерефлексивное самоотождествление с опытом простого человека. Наиболее непримиримые из критиков объявляли это самоотождествление лицемерным (с учетом значительного культурного капитала, которым обладают исследователи), другие указывали на то, что утверждение ценности популярной культуры оборачивается отказом и от собственной субъективности, и от аналитической позиции, в силу чего высказывание о продуктах популярной культуры по сути сводится к признанию того, что «людям это нравится» (Williamson 1986:19; цит. по: McGuigan 1992:76). При этом, по мнению критиков, исследователи популярной культуры упускают из видуто, что альтернативные репрезентации и, соответственно, прочтения с большей вероятностью могут возникать в сфере высокой, нежели популярной культуры (McGuigan 1992:82).

Отвечая на подобные обвинения, Джон Стори вслед за Полом Уиллисом указывал на логику самовоспроизводства иерархий, которая приводит к тому, что большая часть аудитории рассматривает себя как невежественную, нечувствительную и не обладающую способностями для восприятия культурных артефактов, опасающихся утратить позицию доминирования в сфере культуры (Storey 2001:178-179; ср. также: McRobbie 1996:259) ${ }^{19}$. Вместе с тем сторонники исследований популярной культуры показывают, что радикализм их оппонентов связан с воспроизводством традиционных моделей критики массовой культуры, зачастую базирующующейся на антиамериканизме (Ang 1990:256-258; McGuigan 1992:7879). Кроме того, отстаивая идею изучения популярных прочтений, представители cultural studies видят опасность не столько в отказе от рефлексивной позиции интеллектуала, сколько в проекции на тексты популярной культуры собственного опыта интеллектуала, в то время как реальные потребители этих текстов окажутся по сути на заднем плане, в роли тех, кто лишь подтверждает подлинность исследовательского протокола (Morley 1992:332; Morris 1996:15-26).

${ }_{19}$ Важным вкладом в эту критику стали вышедшие в конце 1980-х годов книги Лоуренса Левайна (Levine 1998) и Эндрю Рocca (Ross 1989), представлявшие собой опыт критической истории интеллектуалов. 
В то время как поборники суждений о качестве утверждают невозможность для интеллектуала отказываться от такого рода суждений, адепты концепции популярной культуры указывают на то, что множественность контекстов бытования культурных текстов лишает нас права на спекулятивные ценностные суждения (Storey 2001:172-173). Развивая аналогичный тезис в статье «Problems with Quality» Шарлотта Брансдон (Brundson 1990) показывает, каким образом проблематика суждений о качестве инспирирована телевидением как медиумом, которое тем самым становится вызовом по отношению к культурным иерархиям и ведет к необходимости дифференциации систем критической оценки. При этом она показывает, что в дискуссиях о проблеме качества реакцией на релятивизацию эстетических критериев становится как редукция эстетического суждения к политическому, так и отказ от суждения в принципе (Brundson 1990:73). Майкл Шадсон, текст которого в ряде пунктов предвосхищает систематическое рассмотрение роли культурных исследований для эволюции современного университета в упомянутой выше книге Билла Ридингса, в связи с этим отмечал: «Проблема заключается не в том, чтобы отрицать место суждения и оценки, но в том, чтобы идентифицировать институциональные, государственные (national), классовые, расовые и гендерные предрассудки, глубоко укорененные в предшествующих суждениях, и сделать их доступными для критической переоценки» (Schudson 1987:68).

Третий блок проблем, связанный с темой социального объяснения, касался проблематики автономии культурного анализа. Одним из отправных пунктов логики субъективации был разрыв с экономическим детерминизмом. В связи с этим одним из главных сюжетов в дискуссии о культурном популизме становится взаимоотношение культурных исследований с политэкономией, или, если использовать собственные категории исследователей культуры, отрыв исследований потребления от исследований производства, который в итоге чреват утратой перспективы целостного анализа, необходимой для адекватной интерпретации феноменов культуры (McGuigan 1992:83, 172). Знаковым эпизодом этой дискуссии, продолжавшейся в течение нескольких лет, стала публикация специального раздела в журнале Critical Studies in Mass Communication (№ 1 за 1995 год). Критика в адрес представителей cultural studies была связана с вопросом о степени детерминированности культурных явлений «реальными» отношениями производства, с оценкой значимости тех фактов культурного разнообразия и потребительской активности и, наконец, с возможностью предложить не только описание, но и объяснение этих фактов (Murdock 1989, 1995; Carey 1995; Garnham 1995; Grossberg 1995) 20. Ответом на эту критику стала статья Ларри Гроссберга с характерным названием «Cultural Studies vs. Political Economy: Is Anyone Else Bored with This Debate?» (Grossberg 1995).

${ }^{20}$ Вместе с тем исследователей популярной культуры упрекали не только в разрыве с политэкономией, но и в некритическом восприятии экономических данных. Это, по мнению Саймона Фрита (Frith 1991:104), выражается в том, что отождествлении популярности с коммерческим успехом или, наоборот, в рассмотрении коммерческих провалов как свидетельство неспособности индустрии манипулировать аудиторией. 
Признавая наличие объективных расхождений между политической экономией и культурными исследованиями, американский исследователь показывает, что острота дискуссии обусловлена тем, что критики часто игнорируют тексты исследователей культуры, где эта оппозиция разрешается в продуктивном и рефлексивном ключе (Grossberg 1995; ср. также обсуждение этой проблематики: Fenton 2007).

Другой круг вопросов, связанных с проблематикой социального объяснения, касался соотношения текстуального и этнографического анализа в исследованиях популярной культуры. С одной стороны, предметом критики становится то, что неосознанно (а в некоторых случаях - целенаправленно) такое исследование не выходит за рамки анализа, где текстам приписываются полисемичность и трансгрессивность вне соотнесения с опытом реальных аудиторий (Frith 1991:104; Morley 1992:338-339). Холл неоднократно указывал на то, что увеличение количества постструктуралистских анализов популярной культурной продукции (таких как песни Мадонны или сериалы наподобие «Клан “Сопрано"») становится формой схоластического самовоспроизводства гуманитарной теории ${ }^{21}$. Вместе с тем тезис об активности аудиторий, наоборот, в ряде случаев свидетельствует о недостаточности текстуального анализа в том смысле, что исследователь не учитывает степени принудительности смысловой конструкции текста, обуславливающей характер рецепции (McGuigan 1992:76; Morley 1992:332). Речь идет, таким образом, о том, что идея популярной культуры и активных аудиторий становится легитимацией для деконтекстуализированной трактовки феноменов повседневности, изучение которых оправдывается их протестным потенциалом, который принимается как данность (Ang 1990:246). При этом стимулом к романтизации этих явлений становится сентиментальное принятие чужого опыта, блокирующее его рациональную интерпретацию. В связи с этим Энг писала: «если этнографическое изучение аудиторий хочет развивать критическую функцию, оно не может не обратиться к тому, что социологами было обозначено как проблема соотношения микро- и макро-: к тому, что существуют определенные ограничения для семиотической демократии а lа Фиске и самовыражение происходит в рамках определенных параметров и конкретных условий существования» (Ang 1990:248-249).

\section{ФОРМЫ РЕЦЕПЦИИ ПРОБЛЕМАТИКИ КУЛЬТУРНОГО ПОПУЛИЗМА В КУЛЬТУРНЫХ ИССЛЕДОВАНИЯХ 2000-2010-Х ГОДОВ}

Возвращение к дискуссиям о культурном популизме было связано с изменением социокультурного контекста, обусловленным развитием интернета и рядом других возможностей, создавших условия для вовлечения массовых аудиторий в процессы производства культуры. Потребность в осмыслении этих новых тенденций и

${ }^{21}$ Джеймс Кэри (Carey 1995:83) отмечал, что культурные исследования можно в связи с этим упрекнуть не столько в популизме, сколько в антипопулизме, выражающемся в разрыве с реальной практикой. 
возникающих в связи с их влиянием форм культуры и культурных практик приводит к появлению в лоне культурных исследований таких новых областей знания, как исследования фанатских сообществ (fan studies), исследования новых медиа (new media studies), гибридной культуры (convergence culture) и креативных индустрий (creative industries). Обращаясь к дискуссиям, которые разворачивались в этих областях и вокруг них, мы обнаруживаем, что узловые для дискуссии о культурном популизме проблемы оказываются по-прежнему актуальны как для исследовательской саморефлексии, так и для самоописания этих областей. В подтверждение сказанному мы приведем два примера.

В качестве первого примера мы обратимся к одной из ключевых работ в рамках традиции исследования фан-сообществ - книге британского исследователя Мэтта Хиллса «Fan Cultures». Первая часть книги посвящена выявлению антропологических презумпций и оппозиций, которые возникают в контексте напряжений, появляющихся в ситуации взаимодействия академического исследователя с популярной культурой, представленной в данном случае сообществами фанатов. Несмотря на то, что Хиллс не обращается к дискуссии о культурном популизме и даже не использует этот термин, те сюжеты, которые он обсуждает, непосредственно продолжают тематику этой дискуссии. Критический анализ современных fan studies организован в книге британского исследователя вокруг четырех оппозиций: «консюмеризм - сопротивление», «сообщество - иерархия», «"знание" “оправдание" (justification)» и «фантазия - реальность». Характеризуя первую оппозицию, Хиллс связывает издержки современного состояния исследований фанатских сообществ с дефицитом внимания к социальным и экономическим аспектам как в организации самого фандома, так и в характере взаимодействия с ним академического сообщества, сказывающегося в формах позиционирования исследователей. В частности, он указывает на то, что, утверждая альтруистические ценности участников фандома, исследователи склонны недооценивать коммодифицированный характер последнего (Hills 2002:29-30)22.

Рассматривая оппозицию «сообщество - иерархия», Хиллс анализирует концепции субкультурного капитала, представляющие собой адаптацию теории Бурдье для исследования фандома. Концепция субкультурного капитала позволяет представить сообщества фанатов в качестве альтернативного по отношению к официальной культуре мира, самоутверждение в котором предполагает иные ставки и иные культурные ресурсы (такие, как знание об объекте поклонения). При этом субкультурный капитал не только приобретает (как, например, в концепции Джона Фиске) определенно позитивные коннотации в противовес «официальному», но и в целом его значение оказывается переоценено. Это связано с тем, что, воспроизводя идеологию сообщества фанатов, исследователи склонны игнорировать имеющуюся в сообществе иерархию, а следовательно, значение для участников сообщества социального капитала (характер организации сообщест-

22 Интересно, что Хиллс считает необходимым указать на аналитический потенциал концепции Теодора Адорно, которая традиционно дискредитировалась исследователями культуры как яркое выражение идеи пассивности потребителя культуры. 
ва, сетевые отношения и т. д.) и символического капитала (признание в сообществе, обеспечивающее право говорить от его имени) (Hills 2002:29-30)23.

Рассматривая оппозицию "“знание" - “оправдание"», Хиллс критикует потенциальный редукционизм этнографического анализа фан-сообществ, связанного с презумпцией доверия производимому фанатами знанию. Он пишет:

Я стремлюсь подчеркнуть, что высказывания фанатов не следует воспринимать только лишь как источник данных об их представлениях. Их следует интерпретировать и анализировать, обращая внимание на лакуны и смещения, на сбои в рефлексии и самооописании, а также на повторы и привилегированные повествовательные конструкции, которые связаны с оправданием сообщества (или субкультуры) перед лицом внешней враждебности (Hills 2002:38).

Важным средством для предотвращения редукционизма является автоэтнография исследователя. Она должна не только уравнять его с анализируемым объектом, но и предупредить использование теории в качестве маскировки исследовательской субъективности или воспроизведение устоявшихся презумпций - будь то в форме «здравого смысла» или шаблонных конструкций, обращающихся в рамках академической «критической индустрии». Последние могут иметь различную идеологическую подоплеку, поддерживая как представление о превосходстве академии, так и идеалистические воззрения о прогрессивности фан-сообщества (Hills 2002:51-52).

Наконец, последняя оппозиция - «фантазия - реальность» - отсылает нас к вопросу о культурном статусе опыта фан-сообществ, носящего подчеркнуто аффективный характер. Подходы к анализу аффекта, существующие в рамках культурных исследований (в частности, имеется в виду концепция Ларри Гроссберга), страдают, по мнению Хиллса, недооценкой субъективности, поскольку рассматривают аффекты как социально сконструированные. В поисках более адекватной теоретической рамки он обращается - как и в случае рассмотрения оппозиции «консюмеризм - сопротивление», - к «жесткой» критической теории. В данном случае речь идет о психоанализе, в котором он видит определенный аналитический потенциал, несмотря на характерные для этого подхода аисторичность и склонность клиническому препарированию эмоционального опыта (Hills 2002:6465). Наиболее адекватным, с точки зрения искомого «субъективного поворота», оказывается концепция Дональда Винникотта, которая легитимирует опыт участников фан-сообщества как аффективную игру, выступающую средством поддержания психического здоровья (77-80). Таким образом, обзор проблематики исследований фандома в книге Хиллса обнаруживает явную преемственность по

${ }^{23}$ Вместе с тем Хиллс показывает, что проблемы использования концепции Бурдье применительно к изучению фэндома связаны и с принципиальными ограничениями последней. В частности идея субкультурного капитала предполагает существование организованного сообщества и сложившейся системы «инвестирования». Однако в этой перспективе невозможно описать ситуацию обращения фанатов, поведение которых не носит рационализированного характера (Hills 2002:23). 
отношению к дискуссии о культурном популизме. Обращение к различным пластам этой дискуссии (начиная от вопроса об активных аудиториях и заканчивая значимой для фанатского опыта проблематикой аффекта и приверженности вымышленным мирам) оказывается удобным способом картографирования практики исследований фандома в перспективе логики субъективации. Выявляя проблемные точки различных подходов, Хиллс не только указывает на комплексный характер знания и поведения участников сообщества, но и вскрывает те препятствия для исследования, которые обусловлены интеллектуальными стереотипами исследователей культуры или связаны с их принадлежностью к академическому миру.

Актуализация проблематики культурного популизма в работе одного из ведущих представителей австралийских культурных исследований Грэма Тернера связана не столько с перспективой эмпирического анализа, сколько с осмыслением судьбы культурных исследований как критического проекта и академической дисциплины (Turner 2012) 24 . Впервые Тернер обратился к этой проблематике еще в 1990 году в книге «British Cultural Studies: An Introduction», которая стала одним из первых компендиумов, представивших эту интеллектуальную традицию для международной аудитории. В 2010 годы Тернер возвращается к проблематике культурного популизма в связи с осмыслением отношений культурных исследований и новых областей знания исследований convergence culture, new media studies. Соответствующий текст был впервые опубликован в специальном выпуске журнала Cultural Studies (№ 4/5 за 2011 год) и перекликался с высказываниями других участников этой дискуссии, в частности - авторов вступительной статьи к этому выпуску Джеймса Хея и Ника Коулдри (Hay and Couldry 2011:473-486) $)^{25}$.

Развитие новых областей знания о культуре, возникших во многом благодаря распространению cultural studies, становится, по мнению Тернера, вызовом для последних. Осуществляя активную экспансию в академическое пространство, эти области начинают вытеснять как традиционные специализации в области гуманитарных и социальных наук (например, искусствознание), так и собственно специализации, традиционно существовавшие в cultural studies. Не менее важно и то, что свою генеалогию при этом они возводят к культурным исследованиям, претендуя одновременно на место новых законодателей повестки дня в исследовании современной культуры (Turner 2012:103).

Появление этих областей связано с задачами осмысления новых типов коммуникации, которые характеризуются большим равноправием, активной вовле-

${ }^{24}$ Ср. также аналогичную по своим задачам книгу одного из лидеров культурных исследований в Америке Ларри Гроссберга, где термин «культурный популизм» не используется, однако обсуждается ряд вопросов, связанных с развернувшийся вокруг него дискуссией: вопрос о взаимодействии культуры и экономики, места исследований популярной культуры в культурных исследованиях и т. д. (Grossberg 2010).

25 Похожую аргументацию высказывает и другой видный представитель бирмингемской традиции Дэвид Морли (Christensen and Morley 2014:208-222), отмечая неочевидность новизны нынешней ситуации, проблематизируя степень реальной активности потребителей и т. д. 
ченностью участников и меньшей степенью коммерциализации. Идеологической предпосылкой исследования становится, таким образом, новая модель воспроизводства культуры, альтернативная традиционным представлениям о связи капитализма, масс-медиа и политического порядка, каковые традиционно выступали отправной точкой для представителей cultural studies. С развитием новых медиа и гибридных форм культуры, а также с формирующимися на этой почве культурными индустриями связываются надежды на возможность подлинной популярной культуры, развитие низовой активности и демократического участия, снимающего оппозицию между производителем и потребителем (Turner 2012:104). Тернер находит в этой идеологии характерные признаки культурного популизма: сентиментальное отношение к популярной культуре, тяготение к модному в ущерб неудобным темам, отказ от критической составляющей. Вместе с тем примирение с существующей культурой принимает здесь и специфические формы. В исследованиях новых медиа происходит, по его мнению, переход от характерного для cultural studies акцента на критическом анализе культурной политики в рамках национальных государств к изучению глобального рынка как среды существования новых экономических и культурных форм. Утверждение последних в качестве объектов исследования связано с презумпциями экономического и технологического оптимизма, для которого, по мнению Тернера, нет достаточных эмпирических оснований. Успехи академической институционализации этих новых областей связаны с рыночной валидностью предлагаемого ими знания, которая приобретает особую актуальность в связи с происходящим в последние десятилетия сокращением государственного финансирования университетов. При этом само содержание подобных программ слабо связано с трудами представителей cultural studies и ориентировано не столько на развитие критической рефлексии о культуре, сколько на трансляцию технических навыков, необходимых для самореализации в новых экономических и медийных условиях. Характерно, что, противопоставляя культурные исследования исследованиям новых медиа, гибридных культур и креативных индустрий, Тернер не только подчеркивает связь cultural studies с традиционными дисциплинами, имея в виду их общую ориентацию на развитие навыков теоретической рефлексии, но говорит также и об их «дисциплинарном потенциале», который у новых направлений отсутствует (Turner 2012:116-117).

\section{ЗАКЛЮЧЕНИЕ}

Предпринятый нами анализ дискуссии о культурном популизме носит, безусловно, эскизный характер и может рассматриваться скорее в качестве отправной точки для более подробного анализа затронутых этой дискуссией сюжетов. Тем не менее он подтверждает сформулированную нами ранее (Степанов 2015б) идею о важности учета временной конъюнктуры для понимания эволюции культурных исследований. Дискуссия о культурном популизме показывает, каким образом формирование исследовательской программы cultural studies на рубеже 19801990-х годов было связано с изменениями в социокультурной ситуации, переме- 
нившими не только условия производства знания, но и саму конфигурацию объекта исследования, что стимулировало переосмысление соотношения экономики и культуры, возможностей политической активности, роли интеллектуалов в воспроизводстве культуры и т. д. Другим важным фактором в этой констелляции стала внутренняя логика развития этой интеллектуальной традиции. Развивая логику субъективности, исследования популярной культуры разрабатывают проблематику воображения, удовольствия и потребления. Намеченная нами преемственность культурных исследований 2000-2010-х годов по отношению к этой дискуссии позволяет зафиксировать генеалогию тех проблем, которые сегодня оказываются на повестке дня исследователей культуры - начиная от изучения самоорганизующихся сообществ потребителей, чья активность оказывается важным фактором функционирования культуры, и заканчивая проблематикой самоопределения культурных исследований в условиях нового (неолиберального? неоконсервативного?) мирового порядка, где тема популизма снова привлекает внимание как широкой публики, так и исследователей ${ }^{26}$.

Проблематика культурного популизма интересна тем, что она обнаруживает неоднозначные взаимосвязи идеологического (политического или дисциплинарного) и методологического самоопределения. Ситуация этой дискуссии позволяет, с одной стороны, увидеть, как складывался ореол постмодернизма, который в значительной степени стал стигмой культурных исследований, с другой стороны зафиксировать те проблемные пункты, которые стали отправными точками для переосмысления современной культуры. Обсуждение судьбы cultural studies в ситуации социального изменения оказывается связано с выработкой новых представлений о политических и экономических проекциях культуры и в конечном счете иных антропологических конструкций. Обвинения в популизме и следовании конъюнктуре а также - в противовес этому - в левацком пессимизме и моральном лефтизме, сталкивающиеся в ситуации институционализации и интернационализации cultural studies, указывают на напряжения, возникающие внутри критического проекта.

В методологическом плане эта дискуссия интересна, во-первых, обсуждением антропологических оснований изучения популярной культуры, в центре которого оказывается фигура (активного) потребителя культуры. Во-вторых, исследования популярной культуры остро ставят вопрос об автономии культурного анализа и его дисциплинарном самоопределении. Здесь стоит обратить внимание не только на развитие рефлексивных процедур (например, таких как критика романтизации исследуемых феноменов популярной культуры (будь то культура рабочего класса, субкультурные сообщества или активные аудитории) или редукции социального контекста в рамках различных форм текстуального анализа, рафини-

${ }^{26}$ Свидетельством такого интереса может быть книга Эрнесто Лакло «0n Populist Reason» (Laclau 2002), которая, по мнению Оливера Марчарта (Marchart 2012), дает основания для выработки теории политического протеста, дефицит которой по-прежнему характеризует культурные исследования. Из свежих отечественных публикаций можно обратить внимание на специальный выпуск журнала «Вестник общественного мнения. Данные. Анализ. Дискуссии» (№ 1-2 за 2017 год), посвященный популизму. 
рования социологического воображения в практике рецептивных исследований и т. д.), но и на сам характер дискуссии, сталкивающей различные дисциплинарные перспективы и тем самым выступающей своего рода иллюстрацией методологического потенциала схемы циркуляции культуры, выдвинутой Ричардом Джонсоном. Рассмотрение этой дискуссии в контексте современного состояния поля культурных исследований демонстрирует то, как выдвинутые в ней аргументы рафинируются в рамках исследовательской практики или, наоборот, шаблонизируются в качестве элементов дисциплинарной идеологии ${ }^{27}$.

\section{СПИСОК ЛИТЕРАТУРЫ}

Бахманн-Медик, Дорис. [2015] 2017. Культурные повороты. Новые ориентиры в науках о культуре. М.: Новое литературное обозрение.

Бессмертный, Юрий. 2000. «Многоликая история (Проблема интеграции микро- и макроподходов)». С. 52-61 в Казус-2000, под ред. Юрия Бессмертного и Михаила Бойцова. М.: РГГУ.

Джонсон, Ричард. [1983] 2012. «Так что же такое культурные исследования?». Логос 1:80-135.

Куренной, Виталий. 2012. «Исследовательская и политическая программа культурных исследований». Логос 1:14-79.

Ридингс, Билл. [1997] 2010. Университет в руинах. М.: ГУ-ВШЭ.

Савельева, Ирина и Андрей Полетаев. 2006. Знание о прошлом: теория и история. Т. 2. СПб.: Наука.

Степанов, Борис. 2015а. «Борис Дубин и российский проект социологии культуры». Общественные науки и современность 6:163-173.

Степанов, Борис. 2015б. "“Как беззаконная комета...": культурные исследования в поисках академической идентичности». С. 389-420 в Науки о человеке: история дисциплин, под ред. Ирины Савельевой и Александра Дмитриева. М.: Издательский дом НИУ ВШЭ.

Ang, Ien. 1987. "Popular Fiction and Feminist Cultural Politics." Theory, Culture \& Society 4(4):651658.

Ang, Ien. 1990. “Culture and Communication: Towards an Ethnographic Critique of Media Consumption in the Transnational Media System." European Journal of Communication 5(2):240-260.

Bonnell, Victoria E., and Lynn Hunt, eds. 1999. Beyond the Cultural Turn: New Directions in the Study of Society and Culture. Berkeley: University of California Press.

Brundson, Charlotte. 1990. “Problems with Quality." Screen 31(1):67-90.

Brunsdon, Charlotte, and David Morley. 2005. The Nationwide Television Studies. London: Routledge.

Carey, James. 1995. "Abolishing the Old Spirit World." Critical Studies in Mass Communication 12(1):82-89.

Chamberlain, Craig. 2004. "Cultural Studies Conference to Draw Participants from More than 45 Nations." Illinois News Bureau, June 3. Retrieved December 15, 2017 (https://news.illinois. edu/blog/view/6367/207587).

Chen, Kuan-Hsing, and Stuart Hall. 1996. "Cultural Studies and the Politics of Internationalization: An Interview with Stuart Hall." Pp. 392-410 in Stuart Hall: Critical Dialogues in Cultural Studies, edited by Kuan-Hsing Chen and David Morley. London: Routledge.

Christensen, Miyase, and David Morley. 2014. “New Media, New Crises, New Theories? An Interview with David Morley." Popular Communication 12(4):208-222.

Curran, James. 1990. "The New Revisionism in Mass Communication Research: A Reappraisal." European Journal of Communication 5(2-3):136-139.

Dyer, Richard, Terry Lovell, and Jean McCrindle. 1977. "Soap Opera and Women." Edinburgh International Television Festival Programme.

${ }^{27} 0$ потенциале этой дискуссии для осмысления исследований культуры в России см.: Степанов (2015a). 
Fenton, Natalie. 2007. "Bridging the Mythical Divide: Political Economy and Cultural Studies Approaches to the Analysis of the Media." Pp. 7-31 in Media Studies: Key Issues and Debates, edited by Eoin Devereux. London: Sage.

Ferguson, Marjorie, and Peter Golding. 1997. "Cultural Studies and Changing Times: An Introduction." Pp. xiii-xxvii in Cultural Studies in Question, edited by Marjorie Ferguson and Peter Golding. London: Sage.

Fiske, John. 1987. Television Culture. London: Routledge.

Fiske, John. 1989. Understanding the Popular. London: Unwin Hyman.

Frith, Simon. 1991. "The Good, the Bad, and the Indifferent: Defending Popular Culture from the Populists." Diacritics 21(4):101-115.

Frith, Simon, and Jon Savage. 1992. "Pearls and Swine: The Intellectuals and the Mass Media." New Left Review 198:107-123.

Garnham, Nicholas. 1995. "Political Economy and Cultural Studies: Reconciliation or Divorce?" Critical Studies in Mass Communication 12(1):60-71.

Gray, Ann. 1987. "Reading the Audience." Screen 28(3):24-35.

Gripsrud, Jostein. 1989. “High Culture Revisited." Cultural Studies 3(2):194-207.

Grossberg, Larry. 1995. “Cultural Studies vs. Political Economy: Is Anyone Else Bored with This Debate?" Critical Studies in Mass Communication 12(1):72-81.

Grossberg, Larry. 2010. Cultural Studies in the Future Tense. Durham, NC: Duke University Press.

Hall, Stuart. 1996. "The Meaning of New Times." Pp. 222-236 in Stuart Hall: Critical Dialogues in Cultural Studies, edited by Kuan-Hsing Chen and David Morley. London: Routledge.

Hall, Stuart, and Martin Jacques, eds. 1989. New Times: The Changing Face of Politics in the 1990s. London: Lawrence \& Wishart in association with Marxism Today.

Hay, James, and Nick Couldry. 2011. "Rethinking Convergence/Culture: An Introduction." Cultural Studies 25(4-5):473-486.

Hills, Matt. 2002. Fan Cultures. London: Routledge.

Hobson, Dorothy. 1985. "Slippery Soaps." Edinburgh International Television Festival Programme.

Inglis, David. 2007. "The Warring Twins: Sociology, Cultural Studies, Alterity and Sameness." History of the Human Sciences 20(2):99-122.

Johnson, Richard, Deborah Chambers, Parvati Raghuram, and Estella Tincknell. 2004. The Practice of Cultural Studies. London: SAGE Publications.

Laclau, Ernesto. 2002. On Populist Reason. New York: Verso.

Levine, Lawrence W. 1988. Highbrow/Lowbrow: The Emergence of Cultural Hierarchy in America. Cambridge, MA: Harvard University Press.

Marchart, Oliver. 2012. "Elements of Protest: Politics and Culture in Laclau's Theory of Populist Reason." Cultural Studies 26(2-3):223-241.

McGuigan, Jim. 1992. Cultural Populism. London: Routledge.

McGuigan, Jim. 1997. "Cultural Populism Revisited." Pp. 138-154 in Cultural Studies in Question, edited by Marjorie Ferguson and Peter Golding. London: Sage.

McGuigan, Jim. 2011. "From Cultural Populism to Cool Capitalism." Art \& the Public Sphere 1(1):7-18.

McRobbie, Angela. [1980] 1991. "Settling Accounts with Subculture: A Feminist Critique." Pp. 1634 in Feminism and Youth Culture: From Jackie to Just 17. Boston: Unwin Hyman.

McRobbie, Angela. 1994. Postmodernism and Popular Culture. London: Routledge.

McRobbie, Angela. 1996. "Looking Back at New Times and Its Critics." Pp. 237-261 in Stuart Hall: Critical Dialogues in Cultural Studies, edited by Kuan-Hsing Chen and David Morley. London: Routledge.

Morley, David. 1992. “Populism, Revisionism and The 'New' Audience Research." Poetics 21(4):329_ 344.

Morris, Megan. [1988] 1996. “Banality in Cultural Studies." Pp. 187-196 in What Is Cultural Studies? A Reader, edited by John Storey. London: Arnold.

Murdock, Graham. 1989. "Cultural Studies: Missing Links." Critical Studies in Mass Communication 6(4):436-440. 
Murdock, Graham. 1995. “Across the Great Divide: Cultural Analysis and the Condition of Democracy." Critical Studies in Mass Communication 12(1):89-95.

Nava, Mica. 1987. “Consumerism and Its Contradictions." Cultural Studies 1(2):204-210.

0'Connor, Alan. [1989] 1996. "The Problem of American Cultural Studies." Pp. 187-196 in What Is Cultural Studies? A Reader, edited by John Storey. London: Arnold.

Parker, Holt N. 2011. "Toward a Definition of Popular Culture." History and Theory 50(2):147-170.

Ross, Andrew. 1989. No Respect: Intellectuals and Popular Culture. New York: Routledge.

Schudson, Michael. 1987. “The New Validation of Popular Culture: Sense and Sentimentality in Academia." Critical Studies in Media Communication 4(1):51-68.

Sparks, Colin. 1996. "Stuart Hall, Cultural Studies, and Marxism." Pp. 71-102 in Stuart Hall: Critical Dialogues in Cultural Studies, edited by Kuan-Hsing Chen and David Morley. London: Routledge.

Storey, John. 2001. Cultural Theory, Popular Culture: An Introduction. Harlow, UK: Prentice Hall.

Stratton, Jon, and Ien Ang. 1996. “On the Impossibility of a Global Cultural Studies." Pp. 360-392 in Stuart Hall: Critical Dialogues in Cultural Studies, edited by Kuan-Hsing Chen and David Morley. London: Routledge.

Striphas, Ted. 2002. "Banality, Book Publishing and the Everyday Life of Cultural Studies." International Journal of Cultural Studies 5(4):438-460.

Turner, Graeme. 2003. British Cultural Studies: An Introduction. London: Routledge.

Turner, Graeme. 2012. What's Become of Cultural Studies? London: SAGE Publications.

Warner, William, and Clifford Siskin. 2008. "Stopping Cultural Studies." Profession 14:94-107.

Webster, Duncan. [1990] 1996. "Pessimism, Optimism, Pleasure: The Future of Cultural Studies." Pp. 221-236 in What Is Cultural Studies? A Reader, edited by John Storey. London: Arnold.

Williamson, Judith. 1986. “The Problems of Being Popular." New Socialist 41:14-15.

\section{THE "AXIAL AGE" OF CULTURAL STUDIES: A DISCUSSION ON CULTURAL POPULISM}

\section{Boris Stepanov}

Boris Stepanov is Leading Research Fellow at the Research Centre for Contemporary Culture at Poletayev Institute for Theoretical and Historical Studies in the Humanities and Associate Professor in the School of Cultural Studies, National Research University-Higher School of Economics. Address for correspondence: ul. Staraia Basmannaia, 21/4, Corpus L, Room 505, Moscow, 105066, Russia. bstepanov@hse.ru.

This review essay examines debates on cultural populism among English-speaking cultural theorists in the second half of the 1980s and early 1990s. These debates were inspired by the development of the studies of popular culture and had a significant influence on the transformation of the landscape of cultural studies in the context of their academic and public expansion. The essay analyzes, firstly, the historical conjuncture of the discussion and examines different points of view on cultural studies as a critical theory and research project. Secondly, it points out the significance of this discussion for the interpretation of the present state and perspectives of cultural studies, including such new areas as fan studies, new media studies, and the like.

Keywords: Cultural Studies; Populism; Popular Culture; Subjectivity; Reception Studies; Subcultures; Fan Studies 


\section{REFERENCES}

Ang, Ien. 1987. “Popular Fiction and Feminist Cultural Politics." Theory, Culture \& Society 4(4):651-658.

Ang, Ien. 1990. "Culture and Communication: Towards an Ethnographic Critique of Media Consumption in the Transnational Media System." European Journal of Communication 5(2):240-260.

Bachmann-Medick, Doris. [2015] 2017. Kul'turnye povoroty: Novye orientiry v naukakh o kul'ture. Moscow: Novoe literaturnoe obozrenie.

Bessmertnyi, Iurii. 2000. "Mnogolikaia istoriia (Problema integratsii mikro- i makropodkhodov)." Pp. 52-61 in Kazus-2000, edited by Iurii Bessmertnyi and Mikhail Boitsov. Moscow: RGGU.

Bonnell, Victoria E., and Lynn Hunt, eds. 1999. Beyond the Cultural Turn: New Directions in the Study of Society and Culture. Berkeley: University of California Press.

Brundson, Charlotte. 1990. "Problems with Quality." Screen 31(1):67-90.

Brunsdon, Charlotte, and David Morley. 2005. The Nationwide Television Studies. London: Routledge.

Carey, James. 1995. "Abolishing the Old Spirit World." Critical Studies in Mass Communication 12(1):82-89.

Chamberlain, Craig. 2004. "Cultural Studies Conference to Draw Participants from More than 45 Nations." Illinois News Bureau, June 3. Retrieved December 15, 2017 (https://news.illinois. edu/blog/view/6367/207587).

Chen, Kuan-Hsing, and Stuart Hall. 1996. “Cultural Studies and the Politics of Internationalization: An Interview with Stuart Hall." Pp. 392-410 in Stuart Hall: Critical Dialogues in Cultural Studies, edited by Kuan-Hsing Chen and David Morley. London: Routledge.

Christensen, Miyase, and David Morley. 2014. "New Media, New Crises, New Theories? An Interview with David Morley." Popular Communication 12(4):208-222.

Curran, James. 1990. "The New Revisionism in Mass Communication Research: A Reappraisal." European Journal of Communication 5(2-3):136-139.

Dyer, Richard, Terry Lovell, and Jean McCrindle. 1977. "Soap Opera and Women." Edinburgh International Television Festival Programme.

Fenton, Natalie. 2007. “Bridging the Mythical Divide: Political Economy and Cultural Studies Approaches to the Analysis of the Media." Pp. 7-31 in Media Studies: Key Issues and Debates, edited by Eoin Devereux. London: Sage.

Ferguson, Marjorie, and Peter Golding. 1997. “Cultural Studies and Changing Times: An Introduction." Pp. xiii-xxvii in Cultural Studies in Question, edited by Marjorie Ferguson and Peter Golding. London: Sage.

Fiske, John. 1987. Television Culture. London: Routledge.

Fiske, John. 1989. Understanding the Popular. London: Unwin Hyman.

Frith, Simon. 1991. "The Good, the Bad, and the Indifferent: Defending Popular Culture from the Populists." Diacritics 21(4):101-115.

Frith, Simon, and Jon Savage. 1992. "Pearls and Swine: The Intellectuals and the Mass Media." New Left Review 198:107-123.

Garnham, Nicholas. 1995. "Political Economy and Cultural Studies: Reconciliation or Divorce?" Critical Studies in Mass Communication 12(1):60-71.

Gray, Ann. 1987. “Reading the Audience." Screen 28(3):24-35.

Gripsrud, Jostein. 1989. “High Culture Revisited." Cultural Studies 3(2):194-207.

Grossberg, Larry. 1995. “Cultural Studies vs. Political Economy: Is Anyone Else Bored with This Debate?" Critical Studies in Mass Communication 12(1):72-81.

Grossberg, Larry. 2010. Cultural Studies in the Future Tense. Durham, NC: Duke University Press.

Hall, Stuart. 1996. "The Meaning of New Times." Pp. 222-236 in Stuart Hall: Critical Dialogues in Cultural Studies, edited by Kuan-Hsing Chen and David Morley. London: Routledge.

Hall, Stuart, and Martin Jacques, eds. 1989. New Times: The Changing Face of Politics in the 1990s. London: Lawrence \& Wishart in association with Marxism Today.

Hay, James, and Nick Couldry. 2011. "Rethinking Convergence/Culture: An Introduction." Cultural Studies 25(4-5):473-486. 
Hills, Matt. 2002. Fan Cultures. London: Routledge.

Hobson, Dorothy. 1985. "Slippery Soaps." Edinburgh International Television Festival Programme.

Inglis, David. 2007. “The Warring Twins: Sociology, Cultural Studies, Alterity and Sameness." History of the Human Sciences 20(2):99-122.

Johnson, Richard. [1983] 2012. “Tak chto zhe takoe kul'turnye issledovaniia?" Logos (1):80-135.

Johnson, Richard, Deborah Chambers, Parvati Raghuram, and Estella Tincknell. 2004. The Practice of Cultural Studies. London: SAGE Publications.

Kurennoi, Vitalii. 2012. "Issledovatel'skaia i politicheskaia programma kul'turnykh issledovanii." Logos 1:14-79.

Laclau, Ernesto. 2002. On Populist Reason. New York: Verso.

Levine, Lawrence W. 1988. Highbrow/Lowbrow: The Emergence of Cultural Hierarchy in America. Cambridge, MA: Harvard University Press.

Marchart, Oliver. 2012. "Elements of Protest: Politics and Culture in Laclau's Theory of Populist Reason." Cultural Studies 26(2-3):223-241.

McGuigan, Jim. 1992. Cultural Populism. London: Routledge.

McGuigan, Jim. 1997. “Cultural Populism Revisited." Pp. 138-154 in Cultural Studies in Question, edited by Marjorie Ferguson and Peter Golding. London: Sage.

McGuigan, Jim. 2011. “From Cultural Populism to Cool Capitalism." Art \& the Public Sphere 1(1):718.

McRobbie, Angela. [1980] 1991. "Settling Accounts with Subculture: A Feminist Critique." Pp. 1634 in Feminism and Youth Culture: From Jackie to Just 17. Boston: Unwin Hyman.

McRobbie, Angela. 1994. Postmodernism and Popular Culture. London: Routledge.

McRobbie, Angela. 1996. "Looking Back at New Times and Its Critics." Pp. 237-261 in Stuart Hall: Critical Dialogues in Cultural Studies, edited by Kuan-Hsing Chen and David Morley. London: Routledge.

Morley, David. 1992. “Populism, Revisionism and the 'New' Audience Research." Poetics 21(4):329344.

Morris, Megan. [1988] 1996. “Banality in Cultural Studies." Pp. 187-196 in What Is Cultural Studies? A Reader, edited by John Storey. London: Arnold.

Murdock, Graham. 1989. "Cultural Studies: Missing Links." Critical Studies in Mass Communication $6(4): 436-440$.

Murdock, Graham. 1995. "Across the Great Divide: Cultural Analysis and the Condition of Democracy." Critical Studies in Mass Communication 12(1):89-95.

Nava, Mica. 1987. “Consumerism and Its Contradictions." Cultural Studies 1(2):204-210.

0'Connor, Alan. [1989] 1996. "The Problem of American Cultural Studies." Pp. 187-196 in What Is Cultural Studies? A Reader, edited by John Storey. London: Arnold.

Parker, Holt N. 2011. “Toward a Definition of Popular Culture." History and Theory 50(2):147-170.

Readings, Bill. [1997] 2010. Universitet v ruinakh. Moscow: GU-VShE.

Ross, Andrew. 1989. No Respect: Intellectuals and Popular Culture. New York: Routledge.

Savel'eva, Irina, and Andrei Poletaev. 2006. Znanie o proshlom: Teoriia i istoriia. Vol. 2. Saint Petersburg: Nauka.

Schudson, Michael. 1987. “The New Validation of Popular Culture: Sense and Sentimentality in Academia." Critical Studies in Media Communication 4(1):51-68.

Sparks, Colin. 1996. "Stuart Hall, Cultural Studies, and Marxism." Pp. 71-102 in Stuart Hall: Critical Dialogues in Cultural Studies, edited by Kuan-Hsing Chen and David Morley. London: Routledge.

Stepanov, Boris. 2015a. "Boris Dubin i rossiiskii proekt sotsiologii kul'tury." Obshchestvennye nauki i sovremennost' 6:163-173.

Stepanov, Boris. 2015b. “'Kak bezzakonnaia kometa...': Kul'turnye issledovaniia v poiskakh akademicheskoi identichnosti." Pp. 389-420 in Nauki o cheloveke: Istoriia distsiplin, edited by Irina Savel'eva and Aleksandr Dmitriev. Moscow: Izdatel'skii dom NIU VShE.

Storey, John. 2001. Cultural Theory, Popular Culture: An Introduction. Harlow, UK: Prentice Hall. 
Stratton, Jon, and Ien Ang. 1996. “On the Impossibility of a Global Cultural Studies." Pp. 360-392 in Stuart Hall: Critical Dialogues in Cultural Studies, edited by Kuan-Hsing Chen and David Morley. London: Routledge.

Striphas, Ted. 2002. "Banality, Book Publishing and the Everyday Life of Cultural Studies." International Journal of Cultural Studies 5(4):438-460.

Turner, Graeme. 2003. British Cultural Studies: An Introduction. London: Routledge.

Turner, Graeme. 2012. What's Become of Cultural Studies? London: SAGE Publications.

Warner, William, and Clifford Siskin. 2008. "Stopping Cultural Studies." Profession 14:94-107.

Webster, Duncan. [1990] 1996. "Pessimism, Optimism, Pleasure: The Future of Cultural Studies." Pp. 221-236 in What Is Cultural Studies? A Reader, edited by John Storey. London: Arnold.

Williamson, Judith. 1986. “The Problems of Being Popular." New Socialist 41:14-15. 